\title{
Influence of Different Cooling and Lubrication Techniques on Material Machinability in Machining
}

\author{
Branislav Sredanovic ${ }^{1,}{ }^{*}$ - Gordana Globocki-Lakic ${ }^{1}$ - Djordje Cica 1 - Davorin Kramar ${ }^{2}$ \\ ${ }^{1}$ University of Banja Luka, Faculty of Mechanical Engineering, Bosnia and Herzegovina \\ 2 University of Ljubljana, Faculty of Mechanical Engineering, Slovenia
}

In this paper, a novel approach to the definition of universal machinability is presented. The machinability model is based on analysing the vector of the cutting process performance. The machinability of C45E steel was analysed and evaluated according to the developed machinability definition. As the machinability criteria, cutting force, intensity of tool wear and surface roughness were used.

Analysis of machinability was performed using different cooling and lubrication conditions: conventional flooding, minimum quantity lubrication (MQL) and high-pressure jet-assisted machining (HPJAM). Technological parameters were adjusted to the semi-finish regime, with the use of the highest parameter values possible. During the research, cutting forces, chip shapes, tool wear and surface roughness were monitored and measured. The influence of different cooling and lubrication techniques and the relationships between process performance indicators on C45E steel machinability are analysed.

Keywords: machinability model, high-pressure jet assisted machining, cooling and lubrication

\section{INTRODUCTION}

Material machinability is defined as the ease of material machining with different tools and conditions within economic regimes [1]. As a general definition of material machinability, the following is used: the greatest values of machinability are with those materials with which the smallest cutting forces, vibrations, tool wear and surface roughness processing occur [1]. The goal of machinability testing is finding the optimal regime of material processing and the effective management of the cutting process. The improvement of existing technologies and the developments of new cutting technologies through experimental research are ongoing tasks for researchers.

Analysing machinability is a complicated task because of the large number of influencing factors. Such factors on the material machinability in cutting are the parameters that significantly affect the ease of processing: workpiece material, tool material and geometry, tool machine, processing type, cooling and lubrication fluids properties and delivery, machining condition, etc.

The basic functions of cutting fluid are the reduction of the friction, the reduction of generated heat and the improvement of chip evacuation [2]. The positive effects on machinability are reflected in increasing tool life, reducing energy consumption, improving of the surface roughness, etc. The effect of cooling and lubricating depends on fluid flow parameters, fluid characteristics and delivery technique.
The necessity to machine using less harmful cutting fluids has prompted many researchers to investigate the use of minimum quantity lubrication (MQL). In MQL, lubrication is obtained via the lubricant, while a minimum cooling action is achieved by the pressurised air that reaches the tool/workpiece interface [3]. In MQL, however, secondary characteristics are important. These include their safety properties in environmental pollution and human contact as well as properties in biodegradability, oxidation and storage stability [4].

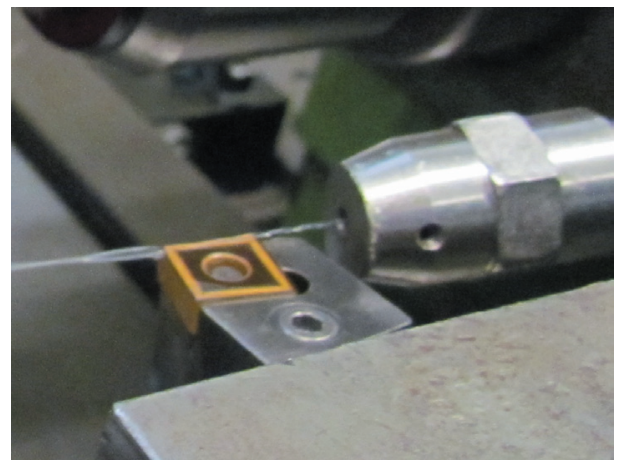

Fig. 1. Jet setup in HPJAM

Compared to conventional cooling, the concept of high-pressure jet-assisted machining (HPJAM) is to inject a high pressure jet of cutting fluid in the cutting zone. The jet is normally directed to the cutting edge at a low angle directly between the rake face and the chip (Fig. 1). HPJAM is beginning established as a method for a substantial increase of removal rate and productivity in machining of advanced materials such as hardened steels used for moulds and constructions, 
Ti-based alloys used in gas turbines and in the aerospace industry. The advantage of this method is reduction of cutting temperature, reduction of tool wear, improvement of chip breakability, etc. [5] and [6].

In this paper, the influence of different cooling and lubrication techniques in turning process with coated carbide tool on steel $\mathrm{C} 45 \mathrm{E}$ machinability is analyzed.

\section{METHOD FOR UNIVERSAL MATERIAL MACHINABILITY DEFFINIG}

Material machinability is defined according to the main criteria. These criteria are the output parameters of the cutting process: tool wear, surface roughness, cutting forces, chip shape, etc., which depend on the input-cutting parameters [1].

Based on analyses of previous approaches of machinability definition, it can be concluded that machinability is defined by one criterion only. Machinability is defined via machinability indexes as the relative estimate of machinability, without units [1]. Some material may have considerable machinability according to one criterion, but exceptionally poor machinability when the other criteria are considered. A complete definition of machinability or absolute machinability is based on the consideration of many criteria simultaneously [1].

In [7], the author described Boulger's specific test for machinability estimation based on process economy. In that paper, Lee's machinability evaluation based on the thermodynamic number was described. Enache et al. [8] developed a "global model" of relative machinability, which contained more criteria. Rao and Gandhi [9] used the matrix and graph theory in a model developed for absolute machinability defining, termed the "matrix model".

In this paper, a novel method of machinability definition, based on vector analysis, is introduced. It considers several machinability criteria [10] and requires a three-axes rectangular coordinate system. Each axis in the system represents an aforementioned criterion (Fig. 2). The criterion values $\left(K_{i}\right)$ are set on the corresponding axis. Criteria whose increasing values decrease the machinability are taken as inputs values in the model. Each axis has a corresponding unit vector $\left(\overrightarrow{k_{i}^{k o}}\right)$ whose length corresponds to the unit value of criterion value (infinite length). The sum of unit vectors yields the control vector $(\vec{C})$, whose direction determines the best uniformity of machinability criteria or the best machinability (Fig. 2).

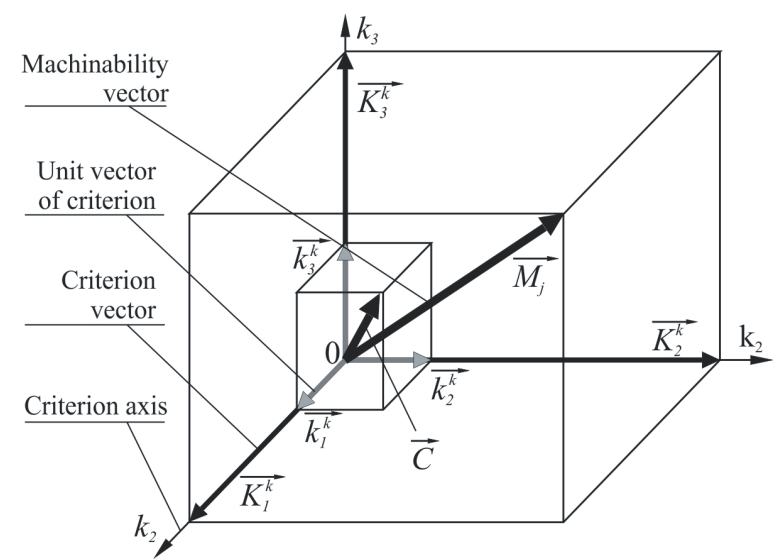

Fig. 2. Machinability vector definition

Based on the criterion values and the corresponding unit vectors, the criterion vector that lies in the appropriate coordinate axis is formed as a scalar product of the unit vector and criterion vector:

$$
\overrightarrow{K_{i}^{K O}}=\overrightarrow{k_{i}^{k o}} \cdot K_{i} .
$$

The machinability vector is the sum of all individual criteria vectors:

$$
\overrightarrow{M_{j}}=\sum_{i=1}^{n} \overrightarrow{K_{i}^{K O}} .
$$

In general, the material whose machinability vector has less intensity and closes smaller angles with a control vector has better machinability [11]. The size of the parallelogram area formed by the machinability vector and its control vector is related to the machinability of materials (Fig. 3.). It can be concluded: material with a smaller parallelogram surface area has better machinability in compare to material with a larger parallelogram surface area.

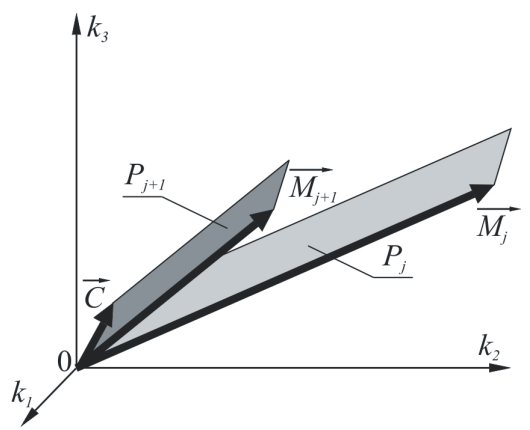

Fig. 3. Area of the parallelogram related to machinability of materials $j$ and $j+1$ 
The size of parallelogram area can be expressed through the value of vector product between the machinability vector and control vector:

$$
P_{j}=\left|\vec{C} \times \vec{M}_{j}\right|=|\vec{C}| \cdot\left|\vec{M}_{j}\right| \cdot \sin \angle\left(\vec{C}, \vec{M}_{j}\right) .
$$

It can be concluded that universal machinability $\left(M_{u}\right)$ is inversely proportional to the area of parallelogram formed by the machinability vector and control vector. Based on established relationships, on Eqs. (3) and (4), it can be written in its final form:

$$
\begin{aligned}
& M_{u}=P_{j}^{-1}= \\
& =\left(\sqrt{K_{1}^{2}+K_{2}^{2}+K_{3}^{2}} \cdot \sqrt{1-\frac{\left(K_{1}+K_{2}+K_{3}\right)^{2}}{\left(K_{1}^{2}+K_{2}^{2}+K_{3}^{2}\right)}}\right)^{-1} .
\end{aligned}
$$

In Eq. (4), as criteria values can be take the measured or calculated values. This values depend on input parameters, on example cutting force is $F=f\left(a_{p}, f, v_{c}\right)$. Eq. (4) has two parts: the first part represents the influence of criteria values and the second part shows the influence of criteria values uniformity on machinability.

\section{EXPERIMENTAL SETUP}

In the experimental research, longitudinal turning operations with different types of cooling and lubrication techniques were used: conventional flooding, MQL and HPJAM. Experiments were conducted on a universal Boehringer lathe with the following characteristics: power of $P=8 \mathrm{~kW}$, maximum spindle speed $n=2240 \mathrm{rev} \cdot \mathrm{min}^{-1}$ and feed $f=1.6 \mathrm{~mm} \cdot \mathrm{rev}^{-1}$. An SNMG $120408 \mathrm{NMX}$ carbide cutting tool for semi-machining was used. The clearance angle was $10^{\circ}$, and the rake angle $0^{\circ}$; the radius of the tool tip was $0.8 \mathrm{~mm}$ with a simple chip breaker. A PSDN 2525 M12 tool holder with an inclination angle of $45^{\circ}$ was chosen (Fig. 4.).

The workpiece material used in experimental research was $\mathrm{C} 45 \mathrm{E}$ carbon steel. Experimental research was performed on a workpiece with dimensions of $150 \times 250 \mathrm{~mm}$. The tensile straight of this material is $\sigma=820 \mathrm{~N} \cdot \mathrm{mm}^{-2}$, the module of elasticity is $E=2 \cdot 10^{3} \mathrm{MPa}$, and the hardness of steel is $45 \mathrm{HRC}$.

All experiments (over 108 experimental measurements with repeating) were carried out using cutting fluid with a $3 \%$ emulsion of vegetable oil. In conventional flooding, a free fall from above is used. A pressure of $p_{C O N}=0.3 \mathrm{MPa}$ and flow rate of $Q_{C O N}=2.01 \cdot \mathrm{min}^{-1}$ was applied.

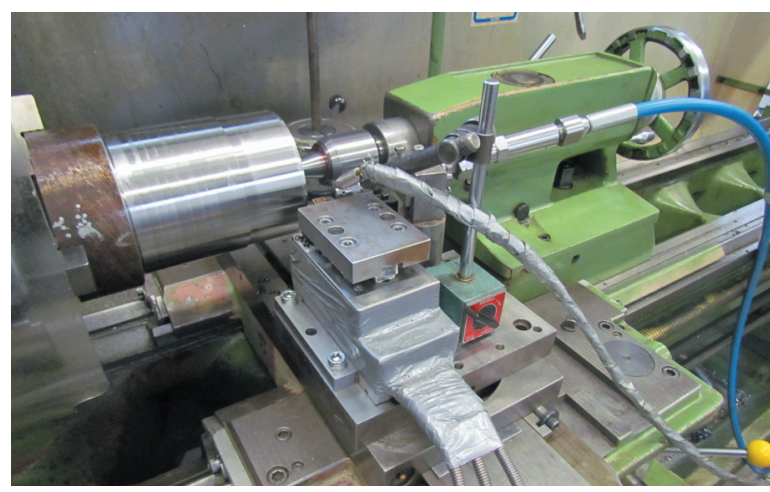

Fig. 4. Experimental setup

With the MQL technique, an external spray system with a was used. Pressure of $p_{M Q L}=0.3 \mathrm{MPa}$ and a flow rate of $Q_{M Q L}=0.00051 \cdot \mathrm{min}^{-1}$ was set. The mixed jet was directed in the cutting zone with its nozzle located $H_{n}=30 \mathrm{~mm}$ away from tool tip, at an angle of $v_{M Q L}=90^{\circ}$ of the cutting edge and at an angle of $\psi_{M Q L}=30^{\circ}$ from clearance face (Fig. 5).

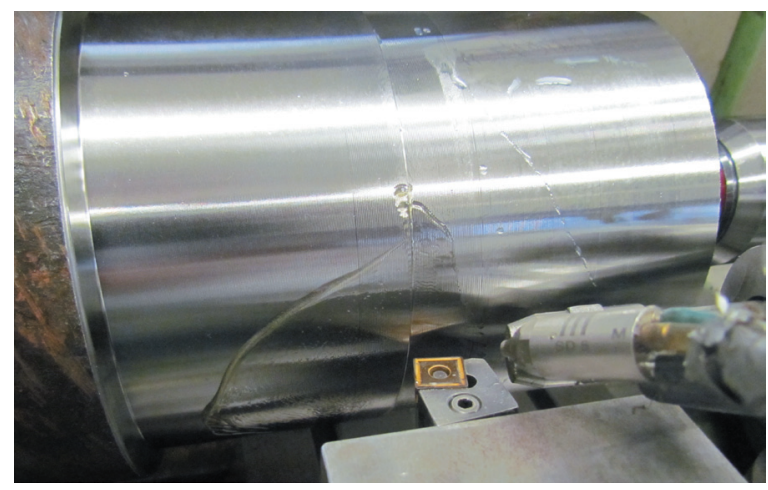

Fig. 5. MQL nozzle setup

In HPJAM, a conventional lathe was fitted with a Hammelmann high pressure plunger pump. The pressure was set at $p_{H P}=50 \mathrm{MPa}$ and the flow rate at $Q_{H P}=2.01 \cdot \mathrm{min}^{-1}$. A standard sapphire orifice with a diameter of $d_{H P}=0.4 \mathrm{~mm}$ (commonly used in waterjet cutting applications) was installed at a distance of $H_{n}=30 \mathrm{~mm}$ from the tool cutting edge in order to assure its use in the core zone of the jet and to avoid variations in the diameter of the jet and the radial distribution of the pressure. The jet was directed to the cutting edge $\left(v_{H P}=90^{\circ}\right)$, and $\psi_{H P}=30^{\circ}$ from clearance face at a low angle (about 5 to $6^{\circ}$ ) with the tool rake face (Fig. 1).

With the goal of achieving an effective material removal process, the cutting speeds and feeds were set higher than recommended. Turning was investigated according to the following input process parameters and levels: 
- $\quad$ Depth of cut $a_{p}[\mathrm{~mm}]: 1.5,2.0,2.5$.

- $\quad$ Feed $f\left[\mathrm{~mm} \cdot \mathrm{rev}^{-1}\right]: 0.224,0.280,0.355,0.400$.

- $\quad$ Cutting speed $v_{c}\left[\mathrm{~m} \cdot \mathrm{min}^{-1}\right]: 210,320,400$.
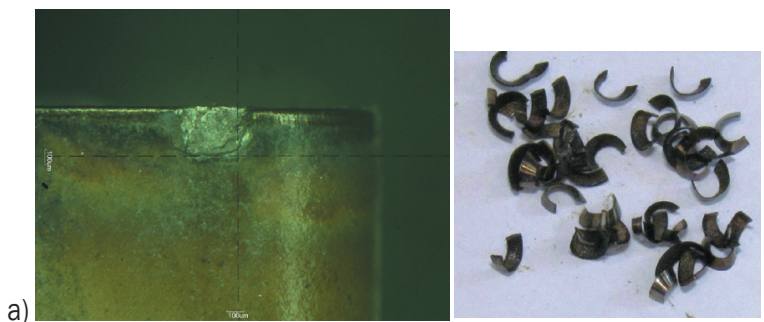

b)
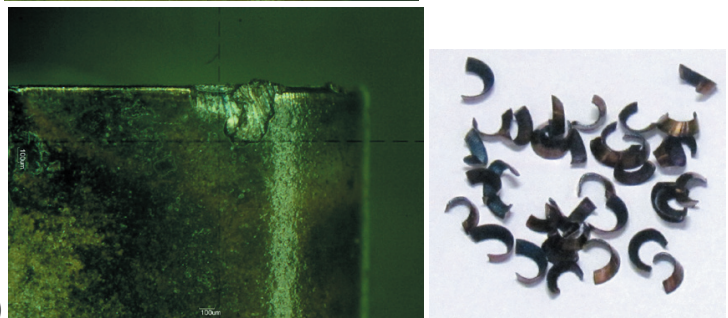

C)
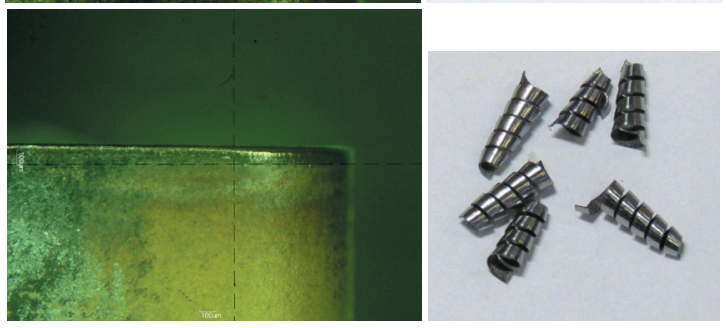

Fig. 6. Flank tool wear and chip shape (ap $=2 \mathrm{~mm}, f=0.28 \mathrm{~mm} \cdot \mathrm{rev}^{-1}, \mathrm{vc}=320 \mathrm{~m} \cdot \mathrm{min}^{-1}$ ) for: a) conventional, b) MQL and c) HPJAM

During the experimental research, crucial process output parameters that describe cutting processes and material machinability were monitored: main cutting force $\left(F_{c}\right)$, feed cutting force $\left(F_{f}\right)$ and passive cutting force $\left(F_{p}\right)$; flank tool wear land width $\left(V B_{B}\right)$ and intensity of tool wear $\left(I_{V B}\right)$; as the surface roughness parameters: arithmetic average height $\left(R_{a}\right)$ and maximum height of the profile $\left(R_{z}\right)$; and chip shape.

\section{ANALYSIS OF EXPERIMENTAL RESULTS}

The best chip shape was obtained via HPJAM (Fig. 6) according the ISO classification [1]. According to its colour, it can be concluded that the impact of generated heat was reduced. Chip shape (conventional and MQL) was similar and was acceptable. Flank tool wear in the conventional and MQL at the end of tool life was extremely poor, as could be observed in the chip shape.

In Fig. 7, a comparison of the three cutting force components values for turning in conventional flooding, MQL and HPJAM cooling and lubrication conditions for different depths of cut and feed rates is shown.
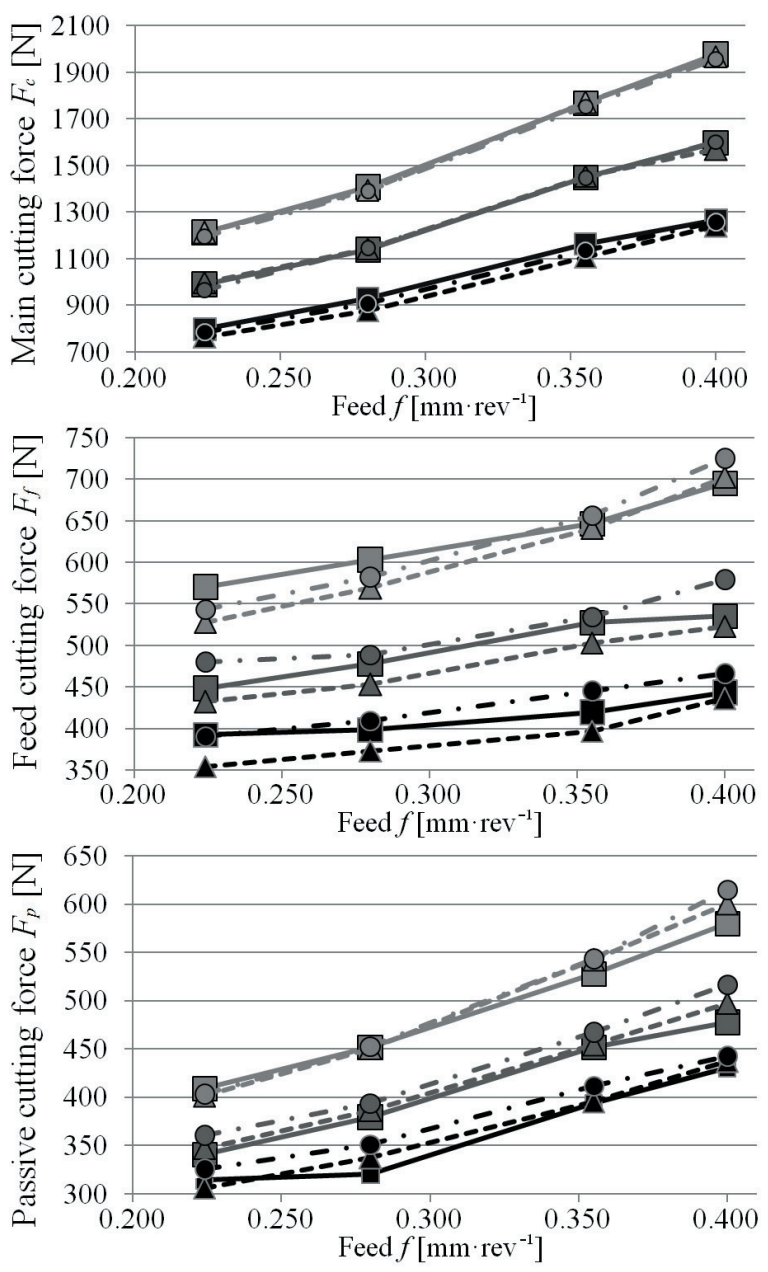

$$
\begin{aligned}
& \square \text { Conv; } a_{p}=2.5[\mathrm{~mm}] \quad-\mathrm{O}-\mathrm{MQL} ; a_{p}=2.5[\mathrm{~mm}] \\
& \square-C o n v ; a_{p}=2.0[\mathrm{~mm}] \quad-0-\mathrm{MQL} ; a_{p}=2.0[\mathrm{~mm}] \\
& \rightarrow-C o n v ; a_{p}=1.5[\mathrm{~mm}] \quad \longrightarrow-\mathrm{MQL} ; a_{p}=1.5[\mathrm{~mm}] \\
& -\triangle-\text { HPJAM; } a_{p}=2.5[\mathrm{~mm}] \\
& \text { - } \triangle-\cdot \text { HPJAM; } a_{p}=2.0[\mathrm{~mm}] \\
& \text {--A--HPJAM; } a_{p}=1.5[\mathrm{~mm}]
\end{aligned}
$$

Fig. 7. Values of cutting forces for different cooling and lubrication conditions in machining of C45E with $v_{c}=320\left[\mathrm{~m} \cdot \mathrm{min}^{-1}\right]$

From the diagrams (Fig. 7), it can be concluded that the values of the main cutting forces for all three cooling and lubrication condition are almost equal. The values of the feed and passive forces were the smallest in the case of HPJAM. In comparison, the values of the aforementioned forces in the MQL were smaller than in the conventional technique. The differences are greater for smaller cutting depths.

Fig. 8 shows the results of tool wear on flank faces for different cooling and lubrication techniques. MQL and conventional techniques show almost the same values of tool wear, about $T=8 \mathrm{~min}$, while 
HPJAM had a four-times longer tool life. Other than this tool wear in HPJAM, conditions are uniform, while in conventional flooding and in MQL conditions some notch wear is recognized (Fig. 6). This is a result of intensive lubrication between the tool rake face and chip, chip deforming and evacuation in the case of HPJAM.

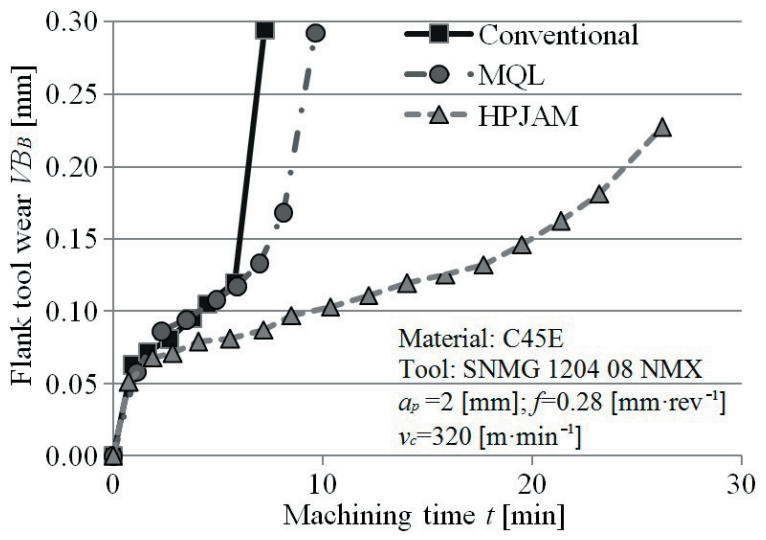

Fig. 8. Tool wear for different cooling and lubrication conditions

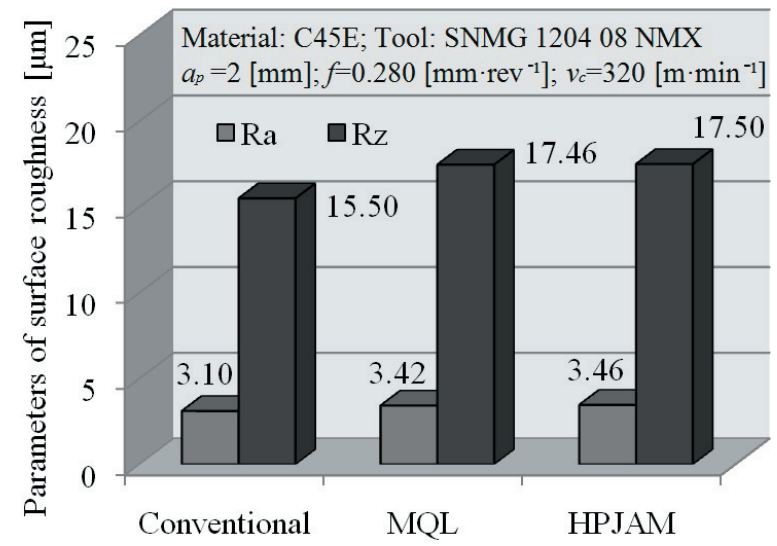

Fig. 9. Surface roughness parameters for different cooling and lubrication conditions

Values of surface roughness for different cooling and lubrication techniques are shown in Fig. 9. For conventional lubrication, surface finish is better than in case of other two techniques used, but surface roughness in MQL and HPJAM is also acceptable.

Predictive regression models for monitored and measured machinability criteria values were developed, and a database was formed. The aforementioned prediction regression models take into account the cutting input parameters: workpiece material, depth of cut, feed, cutting speed, tool geometry, cooling and lubrication type, etc. [11].

According to the new theory described in this paper (the "vector model"), material machinability was analysed. Furthermore, a comparison with Enache's global model [8] and Rao-Ghandi's matrix model [9] and a comparison for different parameter input combinations were performed. In theory of machining, machinability evaluation values are relative values and there are no unit for it.

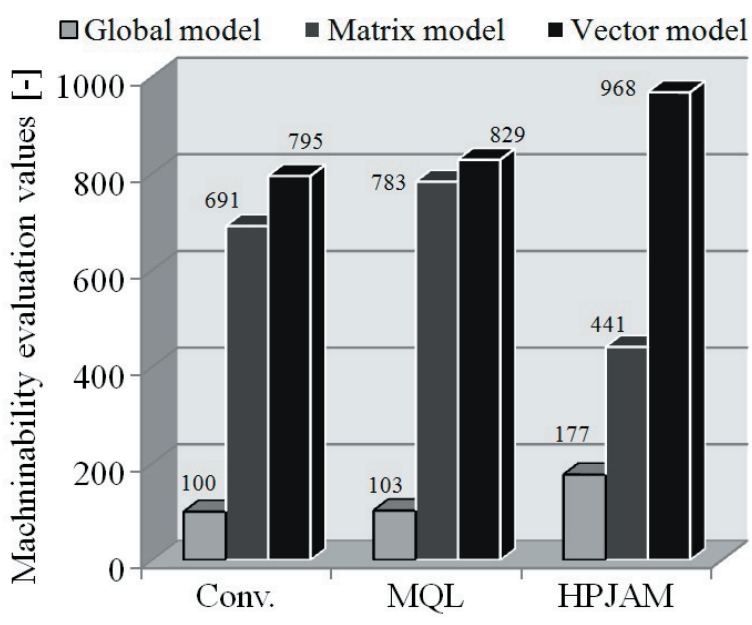

Fig. 10. Comparison of different machinability models for $\mathrm{C} 45 \mathrm{E}$ $\left(a_{p}=2 \mathrm{~mm}, f=0.28 \mathrm{~mm}^{\mathrm{r}} \mathrm{rev}-1, v_{c}=320 \mathrm{~m} \cdot \mathrm{min}^{-1}\right)$

In Fig. 10, a comparison of different material machinability evaluation models is shown. For calculation of machinability evaluation values, cutting force, intensity of flank tool wear and surface roughness were used. The order tendency of input combinations for the new model corresponds to previously developed models. It can be concluded that the output of the newly developed model correspond to the outputs of the matrix and the global model [11].

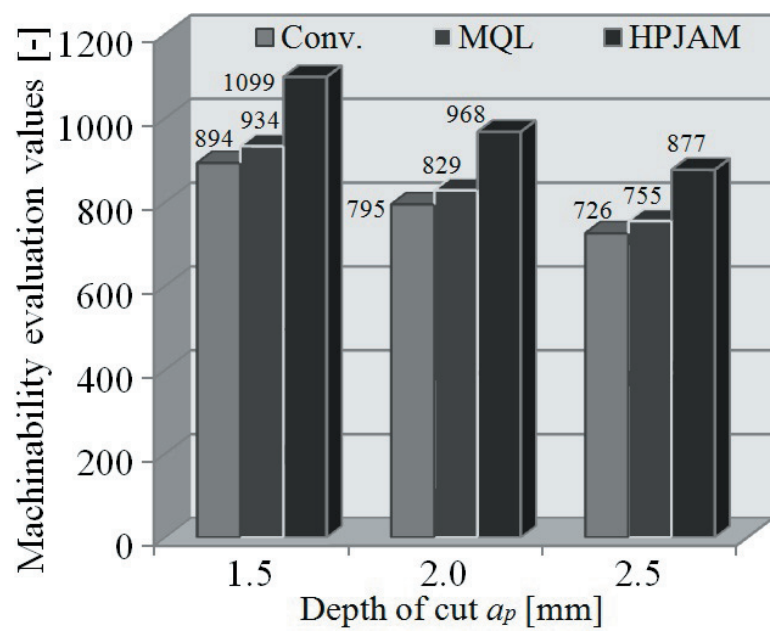

Fig. 11. Comparison of different machinability models for $\mathrm{C} 45 \mathrm{E}$ $\left(f=0.28 \mathrm{~mm}^{\prime} \mathrm{rev}^{-1}, \mathrm{v}_{\mathrm{c}}=320 \mathrm{~m} \cdot \mathrm{min}^{-1}\right)$ 
The machinability evaluation for combinations of investigated inputs is shown in Figs. 11 and 12. With increased feed and depth of cut, increasingly poorer machinability was calculated. The reason for this the highest values of cutting force, tool wear and surface roughness. HPJAM yields the best machinability during machining with the same cutting parameters, because of lower cutting force values and lower flank tool wear values.

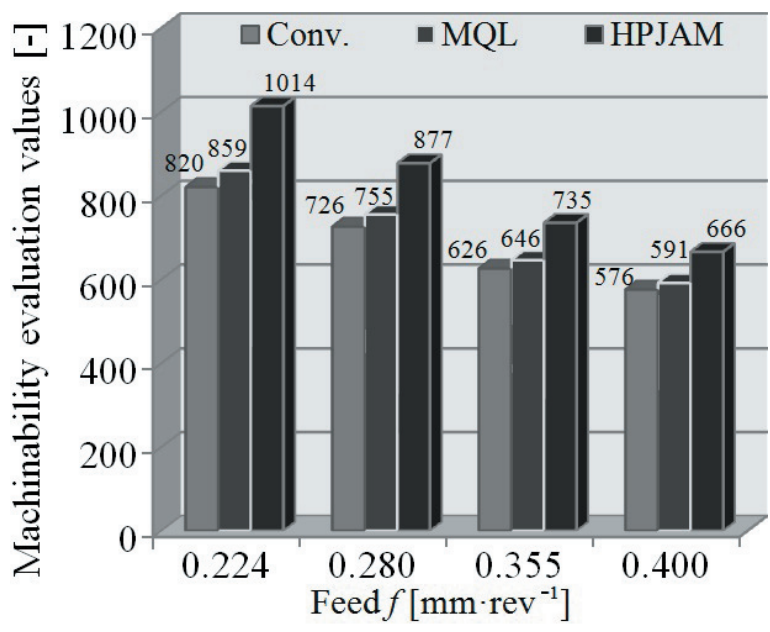

Fig. 12. Machinability evaluation values for different conditions in machining of C45E $\left(a_{p}=2 \mathrm{~mm}, v_{c}=320 \mathrm{~m} \cdot \mathrm{min}^{-1}\right)$

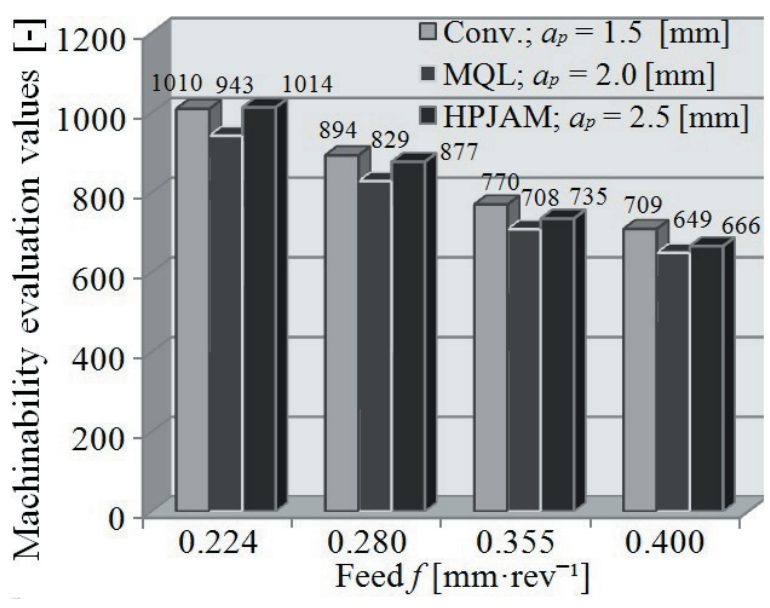

Fig. 13. Machinability evaluation values for different conditions in machining of C45E $\left(\mathrm{v}_{\mathrm{c}}=320 \mathrm{~m} \cdot \mathrm{min}^{-1}\right)$

As shown by the experiments and calculations, turning with conventional flooding at a depth of cut of $a_{p}=1.5 \mathrm{~mm}, \mathrm{MQL}$ at a depth of cut of $a_{p}=2 \mathrm{~mm}$ and with HPJAM at a depth of cut of $a_{p}=2.5 \mathrm{~mm}$ has approximately the same universal machinability (Fig. 13). Based on the values of the developed model of universal machinability, it can be concluded that the highest values of the process parameters can be used in HPJAM.

The same conclusions about the machinability evaluation values for the studied cooling and lubrication techniques using the various criteria of machinability, such as cutting energy, productivity, chip shape, material removal rate (MMR), etc. can be achieved [12].

\section{CONCLUSIONS}

Machinability is an extremely significant factor in industry. It can be estimated by output cutting parameters / machinability criteria, which depend on input cutting parameters. Cutting force, intensity of flank tool wear and parameters of surface roughness were used as the machinability criteria. The newly developed machinability evaluation model shows considerable congruence with previously developed models [8] and [9]. Based on experimental research and using the new model, the machinability of different cooling lubrication techniques can be calculated.

The analysis shows that turning with HPJAM provides the best machinability. Experiments were performed in the use of higher technological parameters values than in previous research and recommendation [5] and [6]. Based on experimental studies, it can be concluded that the tool life during HPJAM turning is four times higher than with MQL and conventional techniques. The same surface roughness was obtained in all three cooling and lubrication techniques. In HPJAM, feed and passive cutting forces are 5 to $10 \%$ lower than with MQL and conventional flooding. Moreover, HPJAM has significant contributions for chip breakability. Based on these facts, we can conclude that HPJAM yields the best results. The operational area for the investigated tool-workpiece combination can be expanded approximately 35 to $40 \%$ in comparison with conventional technology. This expansion is in the increasing of depth of cut, feed and cutting speed. Moreover, a study shown that MQL, as an ecological technology, has slightly better results than conventional lubrication technique.

In the future research, developing of machinability evaluation model in terms of using greater a number of machinability criteria will be investigated. Also, properly inputs and its description in novel model will be investigated. Based on the experimental research, database of technology parameters will be developed. 


\section{ACKNOWLEDGMENTS}

This research is the result of a bilateral project BIBA/12-13-001 between Slovenia and Bosnia and Herzegovina with collaboration between Laboratory for Cutting from Faculty of Mechanical Engineering in Ljubljana and Laboratory for Cutting Technology from Faculty of Mechanical Engineering in Banja Luka.

\section{REFERENCES}

[1] Grzesik, W. (2008). Advanced Machining Processes of Metallic Materials: Theory, Modelling and Application. Elsevier, Amsterdam.

[2] Kopač, J. (2002). Cutting forces and their influence on the economics of machining. Strojniški vestnik Journal of Mechanical Engineering, vol. 48, no. 3, p. 121-132.

[3] Dhar, N.R., Ahmed, M.T., Islam, S (2007). An experimental investigation on effect of minimum quantity lubrication (MQL) in machining AISI 1040 steel. International Journal of Machine Tools \& Manufacture, vol. 47, p. 748-753, DOI:10.1016/j. ijmachtools.2006.09.017.

[4] Leppert, T. (2011). Effect of cooling and lubrication conditions on surface topography and turning process of C45 steel. International Journal of Machine Tools \& Manufacture, vol. 51, p. 120-126, DOI:10.1016/j. ijmachtools.2010.11.001.

[5] Courbon, C., Kramar, D., Krajnik, P., Pusavec, F., Rech, J., Kopac, J. (2009). Investigation of machining performance in high-pressure jet assisted turning of Inconel 718: an experimental study. International
Journal of Machine Tools \& Manufacture, vol. 49, no. 14 , p. 1114-1125, DOI:10.1016/j. ijmachtools.2009.07.010.

[6] Kramar, D., Kopac, J. (2009). High pressure cooling in the machining of hard-to-machine materials. Strojniški vestnik - Journal of Mechanical Engineering, vol. 55, no. 11, p. 685-694.

[7] Theile, E.W., Kuding, K.J., Murphy, D.W., Soloway, G., Duffin, B. (1990). Comparative machinability of brasses, steel and aluminum alloy: CDA's universal machinability index, Publication of CDA, New York.

[8] Enache, S., Strâjescu, E., Opran, C., Minciu, C., Zamfirache M. (1995). Mathematical model for the establishment of material machinability. Annals of CIRP, vol. 44, no. 1, p. 79-82, DOI:10.1016/S00078506(07)62279-3.

[9] Rao, R.V., Gandhi, O.P. (2002). Diagraph and matrix methods for machinability evaluation of works material. International Journal of Machine Tools \& Manufacture, vol. 42, no. 2, p. 321-330.

[10] Sredanovic, B., Globocki, L.G. (2010). Quality monitoring of production systems and processes in form of vector of power. Proceedings of $9^{\text {th }}$ International Scientific and Practical Conference: Research, Development and Application High Technologies in Industry, Saint Petersburg, p. 418-420.

[11] Globocki, L.G., Sredanovic, B., Nedic, B., Cica, Dj., Catic, D. (2011). Development of mathematical model of universal material machinability. Journal of the Balkan Tribological Association, vol. 17, no. 4, p. 501511.

[12] Kramar, D., Sredanović, B., Globočki, L. G., Kopač, J. (2012). Contribution to material machinability definition. Journal of Production Engineering, vol. 15, no. 2, p. 27-32. 